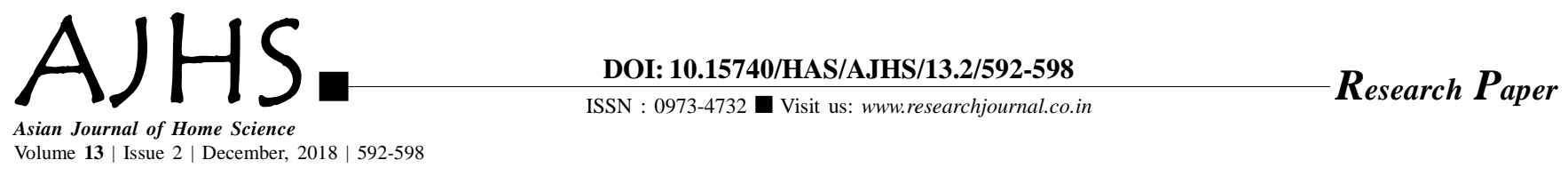

\title{
Endi silk of the new millennium: A scope for development of fashionable dresses
}

\author{
Sunita Boruah and B. Baishya Kalita
}

See end of the paper for authors' affiliations Sunita Boruah

Department of Fashion Design and Technology, Assam Women's University, Jorhat (Assam) India

Email : sunitaboruah182@ gmail.com

Received: 20.06.2018; Revised: 03.11.2018; Accepted: 17.11.2018

ABSTRACT : Endi silk/Eri silk has a potential of emerging as "A silk of the new millennium", providing excellent dimension of scope in design development and produced fashionable dresses with special properties to produce abundant finished products. Considering the different properties and cost of Endi silk and Modal an attempt has been made to produce the structural design fabrics with twill and diamond weaves and explore its properties so that even a common person can enjoy the unique richness of silk with excellent softness and lustre of Modal. A comparative subjective evaluation was done based on fabric quality, viz., aesthetic appearance, luster and texture by the panel of 100 respondents. Respondent opined that all the woven samples have good appearance, soft in hand and smooth in texture. It was observed that cent per cent of respondents found endi-modal blended union fabrics with twill and diamond weaves were high in lustre. The costs of blended yarn and the cost of union fabrics of different proportion were got reduced in comparison to that of 100 per cent endi-silk yarn and controlled endi silk fabrics. Based on the properties, developed dresses may be found suitable for spring-summer seasons. Endi silk union made-ups definitely have better market potential and can create new horizon in the fashion world.

KEY WORDS: Endi silk, Modal, Union fabrics, Twill structured, Dress design

- HOW TO CITE THIS PAPER : Boruah, Sunita and Kalita, B. Baishya (2018). Endi silk of the new millennium: A scope for development of fashionable dresses. Asian J. Home Sci., 13 (2) : 592-598, DOI: 10.15740/HAS/AJHS/13.2/592-598. Copyright@ 2018: Hind Agri-Horticultural Society. 